\title{
ON THE ENGLISH PLUPERFECT: DOES IT REALLY REPRESENT THE PRE-PRETERITE TENSE?
}

\author{
NAOAKI WADA \\ University of Tsukuba
}

\begin{abstract}
This paper argues against the general view that the English pluperfect represents the pre-preterite tense, drawing on Klein's (1992, 1994) compositional semantic analysis of the English perfect tenses. It is claimed that a nonfinite perfect represents the intrinsic meaning of the perfect tense, and that the perfect is temporal-structurally different from the preterite: the former describes a composite situation which consists of two distinct sub-situations, while the latter describes a single situation. Based on these claims, the temporal schemata of the pre-perfect and the pre-preterite tenses are proposed to account for distributional differences between the pluperfect and the preterite which refer to the past-in-thepast time domain. In order to explain why only the English finite present perfect is incompatible with an adverbial of definite time-position like at four or on March 29, a revised version of Klein's P(osition)Definiteness Constraint is offered which can cover more data than Klein's original version.*
\end{abstract}

\section{Introduction}

It has been a prevailing view (e.g. McCawley (1971), Quirk et al. (1985), Salkie (1989), etc.) that the English pluperfect can be interpreted as the past of a simple past (henceforth the pre-preterite tense) as well as the past of a present perfect (henceforth the preperfect tense). The latter is regarded as having the temporal structure in which the perfect is embedded in the past and the former as having the temporal structure in which the preterite is embedded in the past. ${ }^{1}$

* I would like to thank the following people: Minoru Nakau, Yukio Hirose, Nobuhiro Kaga, Robyne Tiedeman and two anonymous EL reviewers for their valuable comments on earlier versions of this paper; Renaat Declerck, who kindly answered my questions about his temporal system; and Robyne Tiedeman and Michael Ribas for answering my questions about English data. All remaining inadequacies are, of course, my own.

${ }^{1}$ I use the term simple past for referring to a past time relative to the speech time; I use the term preterite for referring to the syntactic form. 
They are exemplified in (1) and (2):

(1) When I arrived at the airport, Yoko had gone to Singapore.

(2) I arrived at the hall at five; Mana had played the koto at four.

It is generally said that the pluperfect in (1) has the backshifted temporal structure of the present perfect in (3), whereas the pluperfect in (2) has that of the simple past in (4):

(3) Yoko $\left\{\begin{array}{l}\text { a. has gone } \\ \text { b. *went }\end{array}\right\}$ to Singapore now.

(4) Mana $\left\{\begin{array}{ll}\text { a. } & \text { played } \\ \text { b. } & * \text { has played }\end{array}\right\}$ the koto at four.

As is well known, the finite present perfect in English cannot cooccur with an adverbial of definite time-position (henceforth a DTP adverbial) such as at four or when I arrived at the airport, ${ }^{2}$ whereas the simple past can. This fact might lead us to the claim that since the event time (E) of the pluperfect in (2), which precedes the reference time (R) in the past, is specified by the DTP adverbial at four, this pluperfect is construed as the pre-preterite tense.

Notice here that this line of reasoning is tacitly based on the assumption that the finite present perfect represents the intrinsic meaning of the perfect tense and the perfect tense is the so-called indefinite past, i.e. a past whose time position (or interval) is not identifiable to the hearer. On this assumption, it can be said that the perfect tense, which is indefinite, cannot cooccur with a DTP adverbial because such an adverbial is considered to be compatible only with a definite tense like the simple past. ${ }^{3}$

However, this argument is not well-founded. For one thing, the incompatibility of the finite present perfect with a DTP adverbial does not necessarily prove the indefiniteness of the perfect tense per se.

2 I do not regard a time adverbial like that in (i) as a DTP adverbial:

(i) John HAS left the house at five o'clock.

(Declerck (1991b: 331))

According to Declerck (1991b), at five o'clock in (i) is not a definite indication of time because "it is not interpreted in relation to any particular day referred to in the context." (p. 331) Sentence (i) implies that the situation of John's leaving the house at five o'clock has held at least once within an unspecified period up to now. In this sense this type of time adverbial does not refer to a definite time position. For further discussion, see Declerck (1991b: 331-334).

3 Following Frawley (1992) and others, I consider the English perfect to be a tense. The perfect tense is represented by perfect have plus past participle. 
The definiteness or indefiniteness of a time adverbial is one thing and the definiteness or indefiniteness of a tense is another. For another, the possibility is left that the finite present perfect in English is an exception with respect to cooccurrence with a DTP adverbial; in fact, in English incompatibility with a DTP adverbial is limited to the finite present perfect. Observe the examples in (5):

(5) a. Chris claims to have been in Pontefract last year.

(Klein (1992: 530))

b. Having had a violent row with him on Sunday, John has decided not to see him again for a week.

(Fenn (1987: 230))

c. He may have played yesterday.

(Quirk et al. (1985: 552))

The nonfinite perfects in (5) can all be regarded as present perfects on the grounds that the reference time of the nonfinite perfect is simultaneous with the main-clause time, which is, in turn, simultaneous with the speech time (S). They all cooccur with a DTP adverbial, as the pluperfect in (2) does.

Taking the above matters into consideration, we can get the following generalization in terms of a compositional semantic account of a finite perfect, where the finite perfect can be decomposed into the finite tense (present or past) and the perfect tense:

(6) The perfect tense can cooccur with a DTP adverbial unless some other factor impedes such cooccurrence.

From this generalization, we claim that the cooccurrence of the pluperfect with a DTP adverbial does not provide an argument for allowing the pluperfect to receive the pre-preterite interpretation; the perfect tense per se can go with a DTP adverbial. In order to verify this position, however, the question has to be solved as to what kind of factor prevents the English finite present perfect from cooccurring with a DTP adverbial. I will argue that the factor involved is connected with a peculiarity of the English present tense.

This paper claims that the English pluperfect has only one temporal structure, i.e. the temporal structure of the pre-perfect tense, taking the ground that a nonfinite perfect represents the intrinsic meaning of the perfect tense, from which both a tense-like function and a (perfective) aspect-like function are derived. Some linguists (e.g. Ando (1983), Huddleston (1984), etc.) suggest that if perfect have does not carry the present tense inflection, we have a neutralization of the 
function of the perfect tense (or aspect) and that of the past tense. However, this claim is different from our claim that the English pluperfect represents only the pre-perfect tense, since they also assume that the finite present perfect expresses the nature of the perfect tense. To my knowledge, it is only Fenn (1987) that has suggested that the English pluperfect represents only the pre-perfect tense. However, he also presupposes that the finite present perfect represents the intrinsic semantic value of the perfect tense, claiming that a nonfinite perfect can function as a proform of the past tense. Declerck (1991b) also states that the pluperfect always expresses one temporal meaning, i.e. anteriority in the past, rejecting the view that the pluperfect is ambiguous. However, it is not explicit whether or not the temporal structure of the pluperfect that he has in mind corresponds to that of the pre-perfect tense. Moreover, his analysis is different from ours mainly in two respects: first, he does not admit the dual structure of the perfect tense; second, he does not adopt a compositional semantic account of a finite perfect.

In this paper, I restrict myself to dealing with what Declerck (1991a, b) calls the indefinite (or noncontinuative) perfect, i.e. the perfect whose event time lies entirely before the reference time, since the continuative perfect is not directly relevant to the discussion of this paper. It should also be noted here that I will henceforth use the word present perfect in the sense of 'finite present perfect'.

This paper consists of six sections. Section 2 offers two phenomena that can be viewed as arguments against the claim that the English pluperfect can represent the pre-preterite tense. In section 3, based on Klein's $(1992,1994)$ compositional semantic account, I argue that a nonfinite perfect expresses the intrinsic semantic value of the perfect tense; and I formulate the temporal schemata of the pre-perfect and the pre-preterite tenses, explicating the two phenomena concerning the pluperfect observed in section 2. In section 4, I explain why the English present perfect cannot go with a DTP adverbial by revising Klein's (1992) P(osition)-Definiteness Constraint. Section 5 deals with some empirical facts that my proposal can explain as consequences. Section 6 makes concluding remarks. 
2. Arguments against the Claim that the Pluperfect Can Represent the Pre-preterite Tense

\subsection{Two Phenomena}

In this section, I offer two phenomena that can count as arguments against the claim that the English pluperfect can represent the prepreterite tense.

The first argument concerns the entailment of a resultative state at the reference time $(\mathrm{R})$ in the past. ${ }^{4}$ Let us begin by observing a wellknown pair, given in (7):

(7) a. ${ }^{*}$ I have lost my watch, but $I$ have it with me now. ${ }^{5}$

b. I lost my watch, but I have it with me now.

(7a) is unacceptable because the meaning of the second sentence is contradictory to the meaning conveyed by the first sentence. The present perfect in (7a) entails not only the situation of the speaker's losing his watch, ${ }^{6}$ but also the resultative state of that situation which obtains at the speech time (S), i.e. the state of the speaker's not having the watch at $S$. So we cannot say without contradiction that at $S$ the speaker has the watch that he has lost. Hence the unacceptability of (7a). In (7b), on the other hand, the sentence in the preterite does not necessarily entail such a resultative state. It entails only the event of losing a watch. It is therefore possible that by $\mathrm{S}$ the speaker found the watch that he had lost. Hence the noncontradiction of $(7 b)$.

Keeping in mind this contrast between the present perfect and the simple past, consider the following:

( 8 ) ${ }^{*}$ When I arrived home, I had lost my watch. But I had it with me then. ${ }^{7}$

${ }_{4} \mathrm{I}$ use the term resultative state for denoting a state that holds after, and is affected in some way by, the occurrence of a preceding situation. What kind of resultative state a given verb phrase entails is determined by the idiosyncratic properties of a verb or by the context.

5 Here and below an asterisk is also used to indicate that a given example is semantically anomalous.

6 I use the term situation as a cover-term for anything that can be expressed in a clause, whether it is an action, an event, a process or a state.

7 One might claim that the ungrammaticality of (8) should be ascribed to a semantic property of when; when, when cooccurring with the pluperfect, is sometimes regarded as specifying the event time. However, such an objection is not to the point. Even if when is replaced by by the time, which is always interpreted as specifying the reference time, the grammaticality does not change. Consider the following: 
The adverbial when I arrived home specifies the reference time (R) in the past (or Past 1) and the adverbial then refers to that time. The unacceptability of (8) suggests that the pluperfect cannot represent the pre-preterite tense. Given the fact that the simple past does not necessarily entail a resultative state at $S$, the pre-preterite tense, by definition, does not necessarily entail a resultative state at $R$ in the past. On the pre-preterite interpretation, it is possible to say that by the time he arrived home, the speaker found the watch that he had lost. However, such an interpretation is, in fact, impossible with respect to (8). This is because the pluperfect entails a resultative state at $\mathrm{R}$ in the past. The pluperfect in (8) entails the state of the speaker's not having the watch, which is contradictory to the situation described by the second sentence. Hence, we can present the unacceptability of (8) as an argument against the claim that the pluperfect can represent the pre-preterite tense.

The second argument is based on the fact that we cannot always use the pluperfect when referring to situations in the past time relative to $R$ in the past (henceforth, the past-in-the-past or Past 2). Compare (9a) with $(9 b)$ :

(9) a. ?Max poured a cup of coffee. He had entered the room.

b. Max entered the room. He poured a cup of coffee.

(Lascarides and Asher (1993: 470))

In both (9a) and (9b), the event of Max's entering the room temporally precedes the event of his pouring a cup of coffee. Despite the equal temporal relation between them, $(9 a)$ is odd. If the pluperfect were the pre-preterite tense, which is used to refer simply to a situation in Past 2, (9a) would be perfectly acceptable. We can thus predict that the pluperfect means more than that it simply refers to a situation in Past 2.

This is supported by Lascarides and Asher's (1993: 470-471) statement that $(9 \mathrm{a})$ is improved when accompanied by a further clause

(i ) *By the time I arrived home/in Japan, I had lost my watch. But I had it with me then.

If the pluperfect were really the pre-preterite tense, it would be possible that the speaker once lost his watch and found it again before he reached home/Japan. Hence, we can provide (8) and (i) as evidence that the pluperfect cannot be the prepreterite tense. 
that explains the preceding sentence:

(10) Max poured himself a cup of coffee. He had entered the room feeling depressed, but now felt much better.

(Lascarides and Asher (1993: 471))

It is natural for us to have coffee so as to refresh ourselves when we feel depressed. In this sense the sentence in the pluperfect explains why the event of the preceding sentence happens. Hence, (10) is perfectly acceptable. On the other hand, (9a) is odd in that we can hardly think of the event of entering a room as a reason to drink coffee. Thus, we can say that this phenomenon is an argument against the pre-preterite interpretation of the pluperfect.

\subsection{Current Relevance}

The above observations suggest that the pluperfect requires some special environment where it occurs, that is, an environment where the pluperfect occurs is highly restricted. Why is it so? A possible answer to the question is that the pluperfect expresses a close link between a situation in Past 2 and a situation in Past 1. In the first sentence of (8), the resultative state, which comes from the preceding situation in Past 2 (i.e. the event of the speaker's losing his watch), obtains at the reference time in Past 1 , so there exists a link of relevance between the situation in Past 2 and the situation in Past 1 . In (10) what the pluperfect describes is that there is a link of relevance between the event of Max's entering the room feeling depressed (in Past 2) and the event of his pouring coffee (in Past 1); the resultative state of the former situation is easily regarded as inducing the latter situation.

This kind of close relationship is regarded as the property of current relevance, which is characteristic of the present perfect. Then, what is the definition of current relevance? Following Inoue (1979), I regard current relevance as "a condition of 'repeatability' on the situation described in the topic proposition" (p. 574) at the speech time. By this she means that "the relationship between the proposition in the present perfect and the one in the topic of discourse is that of entailment in a broad sense, supplemented by the so-called pragmatic presuppositions, i.e. the speaker's assumptions in uttering a sentence." (p. 577) Observe the following:

(11) Daniel Jones has done linguistic work in colonial India.

(Inoue (1979: 577)) 
Since Daniel Jones is dead now, (11) is unacceptable in a discourse topic like that of Daniel Jones' engaging in various activities: the situation of his doing linguistic work is not repeatable in such a discourse topic at S. A possible discourse topic for (11) is one about linguistic working in colonial territories; since colonial territories exist now, the situation of his doing linguistic work there can be entailed by, and thus repeatable in, such a discourse topic at $S$. In this sense, the present perfect expresses a link of relevance between the situation in Past 1 (e.g. the situation of Daniel's doing linguistic work in colonial India) and the situation in the present (e.g. the situation of colonial territories still existing).

Since the present perfect in (11) is the experiential perfect, we have to examine the resultative perfect. Let us repeat (3a) as an example:

(3) a. Yoko has gone to Singapore now.

A discourse topic appropriate for (3a) is one about Yoko's recent activities (in this case we assume that Yoko is alive). We can regard the proposition described by the present perfect (i.e. Yoko's going to Singapore) as being entailed by the proposition in that discourse topic, so the former is repeatable in the latter at the speech time.

Note that what kind of resultative state a given perfect conveys is determined on the basis of the lexical properties of a verb (phrase) or the interplay between a verb phrase and the context. Thus, the resultative state in (3a) is the state of Yoko's not being in the place where the speaker is; the resultative state in (11) is the state affected in some way by Daniel's doing linguistic work in colonial India.

Let us go back to the pluperfect. We will first look at (8). If we remove the second sentence from (8), then the sentence in the pluperfect will be acceptable in a discourse topic like that of the speaker's hard luck at a certain time (i.e. R) in the past; the proposition described by the pluperfect (i.e. the speaker's losing his watch) is entailed by, and thus repeatable in, that discourse topic. Its resultative state is regarded as explaining why the speaker is in a bad mood. Let us then observe (10) again. A possible discourse topic is the following: Max's doing something for a change at a certain time (i.e. R) in the past. The proposition described by the pluperfect (i.e. Max's entering a room feeling depressed) is entailed by that discourse topic, and its resultative state can be regarded as a state suitable for that topic.

From what we have seen, we can claim that the pluperfect is parallel 
to the present perfect with respect to current relevance. This kind of parallel can be regarded as an argument for our suggestion that the pluperfect should be the pre-perfect tense. Since the pre-perfect and pre-preterite tenses are defined as the backshifted versions of the present perfect and the simple past respectively, the pre-perfect tense also implies current relevance (in this case the continuing relevance to $\mathrm{R}$ in the past), while the pre-preterite tense does not. If the pluperfect were the pre-preterite tense, it would not require a special environment like (10); it would freely appear in such an environment as (9a) or (8). We can therefore claim that the pluperfect represents the temporal structure of the pre-perfect tense, not that of the pre-preterite tense.

In this section, we have observed two phenomena that can be regarded as arguments against the claim that the pluperfect can represent the pre-preterite tense. In order to demonstrate that the phenomena stem necessarily from the temporal structure of the preperfect tense (represented by the pluperfect), I will explicitly formulate the temporal schemata of the pre-perfect and the pre-preterite tenses in the next section.

\section{A Proposal}

3.1. Nonfinite Perfect Represents Temporal Structure of Perfect Tense Itself

First of all, I claim, drawing on Klein's (1992, 1994) compositional semantic analysis, that a nonfinite perfect represents the temporal structure of the perfect tense per se.

Klein regards a finite verb as the combination of two time components, i.e. the finite component and the nonfinite component; and he considers that the former is associated with the time for which the claim is made (i.e. the topic time, which functions as the reference time in Klein's system), while the latter is associated with the time which specifies the position of a given situation. In the finite verb cried in Mary cried, the finite component marks what Klein calls assertion (represented by the past tense morpheme -ed) and the nonfinite component contributes to the description of the situation of Mary's crying (represented by the base form cry).

Keeping this in mind, let us consider the finite perfect. The finite perfect is considered to be the combination of the tense morpheme and the form of perfect have plus past participle. The former is associated 
with the finite component and the latter with the nonfinite one: in the case of the present perfect the finite component is represented by the present tense morpheme (i.e. zero morpheme or $-s$ ) and the nonfinite component by the perfect form.

One might take the finite component for the finite tense. In order to avoid confusion, I will henceforth use the term absolute tense component for the finite component and relative tense component for the nonfinite component. The reason is that the temporal position of the finite-component element is deictically related to the speech time (S), whereas the temporal position(s) of the nonfinite-component element(s) is (are) anaphorically related to another (preestablished) time. $^{8}$ Thus, the present and the past tenses (represented by tense morphemes) are regarded as absolute tenses on the grounds that their position is deictically related to $S$; whereas the perfect tense can be viewed as a relative tense in that its position is anaphorically related to the time established by an absolute tense. In this view, the present perfect and the pluperfect are semantically decomposed as follows:
a. Present Perfect: PRESENT TENSE+PERFECT TENSE
b. Pluperfect : PAST TENSE +PERFECT TENSE

Under this assumption, in order to focus on the temporal structure of the perfect tense per se, we have only to consider a nonfinite perfect; for a nonfinite perfect does not have any tense morpheme. Thus, observe (5) again:

(5) a. Chris claims to have been in Pontefract last year.

b. Having had a violent row with him on Sunday, John has decided not to see him again for a week.

c. He may have played yesterday.

As is clear from (5), nonfinite perfects go with DTP adverbials. We can thus say that the perfect tense itself can cooccur with a DTP adverbial. One might say that nonfinite perfects like those in (5) are proforms of the past tense. However, in fact a nonfinite perfect with a DTP adverbial can be viewed as the perfect tense. According to Klein (1994: 166-167), a nonfinite perfect with a DTP adverbial requires the reference time $(R)$ to fall in the posttime of a given situation

8 I assume two absolute tenses, i.e. the present tense and the past tense, and three relative tenses, i.e. the anterior tense, the simultaneous tense and the posterior tense. The perfect serves as an anterior tense. English has two ways of expressing anteriority: the preterite and the perfect. 
(i.e. the event time (E)). Thus, for example, in (5a) $R$ falls in the posttime of Chris' being in Pontefract last year. This temporal relation between $\mathrm{R}$ and $\mathrm{E}$ is characteristic of the perfect tense within Reichenbach's (1947) system. It can thus be concluded that the perfect tense itself goes with a DTP adverbial. This conclusion is one of the merits of my proposal in that we do not have to assume two distinct temporal structures (i.e. the perfect and the past tenses) in one form (i.e. perfect have + past participle).

\subsection{The Perfect Represents Composite Situation}

In this subsection, I will argue that the perfect represents a composite situation which is comprised of two distinct sub-situations, while the preterite represents a single situation.

Following Nakau $(1985,1994)$, I assume that the situation with which the perfect tense is associated consists of two sub-situations with one anterior to the other: ${ }^{9}$ the preceding sub-situation is associated with past participle and the following with perfect have. The former can be an action, an event, a state of affairs, etc.; on the other hand, the latter always designates a resultative state by virtue of the state property of perfect have. For convenience' sake, I use E as the symbol of a preceding situation and $\mathrm{E}+$ as the symbol of a corresponding resultative state.

Under this assumption, we can stipulate that the semantic value of the perfect tense is true if and only if a given situation $E$ happens/obtains before the reference time (R) and a corresponding resultative state $\mathrm{E}+$ obtains at that $\mathrm{R} .{ }^{10}$ Consider, for instance, (13):

(13) Mana seems to have played the koto.

This nonfinite perfect is interpreted as follows: the situation $E$ of Mana's playing the koto happens before the $\mathrm{R}$ in the present (i.e. the main-clause time), which is simultaneous with the speech time (S), and a corresponding resultative state E+ (e.g. the state of Mana's being exhausted because of the practice of the koto) obtains at that $\mathrm{R}$.

The dual structure of the perfect is verified by the fact that a given

9 Frawley (1992) and Parsons (1990) also argue for the dual structure of the event frame of the perfect: the situation that the perfect describes consists of two subsituations. See Frawley (1992: 346-348) and Parsons (1990: 234-236) for details.

${ }^{10}$ I use the term happen in the sense of 'materialize' or 'come to existence' and the term obtain in the sense of 'being in existence'. 
situation $\mathrm{E}$ and a corresponding resultative state $\mathrm{E}+$ can both be specified by a DTP adverbial. The nonfinite perfects in (5) are representative examples of E-specifying. In (5a), for example, the DTP adverbial last year specifies the situation $\mathrm{E}$ of Chris' being in Pontefract in the past, not the resultative state $\mathrm{E}+$ in the present (e.g. the state of Chris' being in another place). Now, observe (14) and (15), which are representative examples of E+-specifying:

(14) John may have already met Sue when he married Cynthia.

(McCawley (1971: 101))

(15) This day week I hope to have finished my work.

(Jespersen (1931: 89))

In (14) the DTP adverbial when he married Cynthia specifies the resultative state $\mathrm{E}+$ which obtains at $\mathrm{R}$ in the past, not the situation $\mathrm{E}$ of John's meeting Sue. The same observation applies to (15).

Let us turn to the preterite. The preterite represents a single situation. We can thus stipulate that the semantic value of the preterite (representing the simple past) is true if and only if a given situation $\mathrm{E}$ happens/obtains before the speech time (S). Consider, for instance, a sentence like Yoko played tennis yesterday. What is relevant to the truth value of this sentence is whether or not the situation E of Yoko's playing tennis happens yesterday; whether or not a corresponding resultative state E+ (e.g. the state of Yoko's being exhausted) obtains at $\mathrm{S}$ is an irrelevant matter.

\subsection{Temporal Schemata of Pre-perfect and Pre-preterite Tenses}

This subsection aims to explicitly formulate the temporal schemata of the pre-perfect and the pre-preterite tenses. It is certain that we need a functional time like Reichenbach's reference time $(\mathrm{R})$ in order to fully represent the temporal schema of a given tense. I agree with Reichenbach in this respect. Note, however, that Reichenbach's $R$ is a complex which consists of at least two different concepts (see Declerck (1991b: 225-232) for further discussion): ${ }^{11}$ one is the basic time point which functions as a guidepost from which we locate a

11 Reichenbach's (1947) tense system has been criticized in some respects by many linguists (see Binnick (1991), Declerck (1991b), Klein (1992) and Nakau (1985, 1994), etc.). The same criticism basically holds for Hornstein's (1990) tense system, since it is based on Reichenbach's tripartite tense system, which consists of S, E and R. See Binnick (1991: 344) for further discussion. 
situation (or situations) on the time line; another is a speaker's focus, which is located on the time of situation to which the speaker's special attention is being paid in order for the hearer to fully understand what the speaker is going to convey. ${ }^{12}$ Following Declerck (1991a, b), I call the former notion time of orientation $(\mathrm{O})$ and the latter temporal focus (TF). ${ }^{13}$

To illustrate this point, consider the following:

(16) a. Yoko has gone to Singapore now. $(=(3 a))$

b. Yoko went to Singapore last week.

In both (16a) and (16b), the situation E of Yoko's departure for Singapore is located in the past; and we locate the situation from the time of orientation in the present (in this case the speech time). However, the position of TF in (16a) is different from that of TF in (16b). In (16b) the TF is fixed on the situation $E$ itself in the past. In (16a), by contrast, the TF is fixed on the resultative state $\mathrm{E}+$ of Yoko's not being in the airport, which obtains at $\mathrm{S}$, i.e. the $\mathrm{O}$ in the present. We can thus say that in the case of the simple past the $\mathrm{O}$ is equivalent to $\mathrm{S}$, on the one hand, and the TF is located on the $\mathrm{E}$ in the past, on the other; whereas in the case of the present perfect the $O$ is equal to $\mathrm{S}$, on the one hand, and the TF is located on the $\mathrm{E}+$ which obtains at $\mathrm{S}$, on the other.

I am now in a position to formulate the temporal schemata of the pre-perfect and the pre-preterite tenses within our temporal system. In both cases $\mathrm{O}$ is located in the past (Past 1); $\mathrm{E}$ is located in the pastin-the-past (Past 2). In contrast, the position of TF is different: in the case of the pre-preterite the TF is situated on the $\mathrm{E}$ in Past 2; in the case of the pre-perfect the TF is situated on the $\mathrm{E}+$ which obtains at the $\mathrm{O}$ in Past 1. Both of the tenses are schematized as follows: ${ }^{14}$

12 As a third concept, Declerck admits established time, which is the time point or span referred to by a time adverbial or by the context. Since this kind of time is not directly relevant to the purpose of the present paper, we ignore it. See Declerck (1991b: 250-252) for details.

13 Declerck (1991b: 18) defines the time of orientation (O) as being used for any time that functions as the origin of a temporal relation. The speech time is considered to be an unmarked $O$ or the first $O$. Declerck (p.c.) defines the temporal focus (TF) as the time that the speaker focuses his attention on.

14 An anonymous reviewer has pointed out an alternative approach without using $\mathrm{E}+$, suggesting that the $\mathrm{O}$ on which the TF is situated should be substituted for the $\mathrm{E}+$ in the use of the perfect. On this approach, the schema of the pre-perfect tense will be as follows: 
(17)
a. TF
$\downarrow$
$\mathrm{E}-\mathrm{E}+, \mathrm{O}-\mathrm{S}$ (Pre-perfect)
b. TF

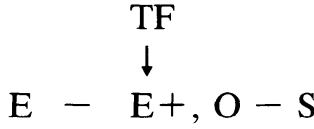
$\downarrow$
$\mathrm{E}-\mathrm{O}-\mathrm{S}$ (Pre-preterite)

The situation referred to by an arrow is the target situation on which the TF is fixed. The pluperfect has the temporal schema of the preperfect tense, not that of the pre-preterite tense. As is predictable from (17a), the temporal schema of the pre-perfect tense entails a resultative state $\mathrm{E}+$ and thus implies current relevance (i.e. the continuing relevance of a preceding situation $E$ to the $O$ in the past) because of the presence of a corresponding resultative state $\mathrm{E}+$, i.e. an element of the temporal structure of the perfect tense. Note, in passing, that in (17) the time of orientation $(\mathrm{O})$ in the past corresponds to the reference time in the previous subsections.

(i)<smiles>FO[In]S</smiles>

Although this schema may work, we will not adopt this suggestion for the following two reasons. First, I claim that $\mathrm{E}+$ and $\mathrm{O}$ are different notions. Let us consider the following discourse:

(ii) I arrived at Tokyo Station at eleven; she had already left there. The temporal relations in (ii) are schematized in (iii):

(iii) First Sentence :

Second Sentence: $\mathrm{E}-\mathrm{E}+, \mathrm{O}-\mathrm{S}$

The vertical line represents simultaneity. As is clear from (iii), the $\mathrm{O}$ of the second sentence is the time indicated by the situation $\mathrm{E}$ of the first sentence (i.e. the speaker's arrival) and functions as the guidepost from which we locate the whole situation (symbolized by E-E+) with which the perfect tense is associated. In the second sentence, the E+ is a part of the semantic structure of the perfect tense, whereas the $\mathrm{O}$ is not. Second, $\mathrm{I}$ argue that TF and $\mathrm{E}+$ are also different notions: $\mathrm{TF}$ is a functional notion whereas $\mathrm{E}+$ is a semantic notion. The reason why the TF is always situated on the E+ in the use of the perfect tense is due to Grice's (1975) Maxim of Quantity: if we mean to situate the TF on the E itself, we will use the preterite, i.e. a simpler form in terms of temporal structure, and do not bother to use the perfect, i.e. a more complex form; we can thus infer that using the perfect means trying to convey the information that we cannot convey by the preterite, namely, that the TF is located on the E+. 


\subsection{Explanation}

In this subsection, I will demonstrate that our temporal schema of the pre-perfect tense illustrates the two phenomena with respect to the pluperfect shown in section 2. First of all, the unacceptability of (8) is predictable from the temporal structure of the pre-perfect tense. Let us repeat (8):

( 8 ) *When I arrived home, I had lost my watch. But I had it with me then.

The unacceptability of (8) is ascribed to the contradiction between the first and the second sentence. The temporal structures of both sentences in (8) are schematized in (18). For convenience' sake, we omit the representation of TF in (18) and (19):

(18) First Sentence : $\mathrm{E}-\mathrm{E}+, \mathrm{O}-\mathrm{S}$

$$
\text { Second Sentence: } \quad E-S
$$

The vertical line symbolizes a relation of simultaneity. In the first sentence, the $\mathrm{O}$ in the past is specified by when I arrived home.

The relationship between the two schemata in (18) makes it clear why (8) is unacceptable. The schema of the first sentence means that the resultative state $\mathrm{E}+$ of the speaker's not having the watch obtains at the $\mathrm{O}$ in the past; on the other hand, the schema of the second sentence shows that the situation E of the speaker's having the same watch obtains at that time. Contradiction then arises; hence the unacceptability of (8).

Let us then consider the fact that we cannot always use the pluperfect when referring to a situation in the-past-in-the past (Past 2). I repeat (9a) here:

(9) a. ?Max poured a cup of coffee. He had entered the room.

The oddity of $(9 \mathrm{a})$ is due to a pragmatic reason: the unnaturalness of the relation between the first and the second sentence. The temporal structures of both sentences in (9a) are diagrammed in (19):

(19) First Sentence : $\mathrm{E}-\mathrm{S}$

Second Sentence: $\mathrm{E}-\mathrm{E}+, \mathrm{O}-\mathrm{S}$

The $\mathrm{E}$ of the first sentence, which denotes the situation of Max's pouring coffee, occupies the same time as the $\mathrm{E}+$ of the second sentence, which denotes the resultative state of Max's having entered a room. Since the latter is not contradictory to the former, (9a) is not 
bad from the point of view of temporal structure. From the point of view of world knowledge, however, it is difficult to regard the result of entering a room as inducing us to want coffee. (9a) is thus pragmatically odd. This line of reasoning is verified by the acceptability of (10). It is natural for us to think of the resultative state of someone's feeling depressed after having entered a room as a motivation to have coffee.

A summary may be helpful here. First, I have argued that a nonfinite perfect represents the intrinsic semantic value of the perfect tense. Secondly, I have claimed that the perfect represents a composite situation and the preterite a single situation. Finally, I have formulated the temporal schemata of the pre-perfect and the prepreterite tenses, so that we have explained why the environments are restricted where the pluperfect can be used.

\section{Incompatibility of Present Perfect with DTP Adverbial}

In order to justify the position that the English perfect per se can go with a DTP adverbial, I will explain why the English present perfect cannot cooccur with an adverbial of definite-time position (a DTP adverbial) by a revised version of Klein's (1992) P(osition)-Definiteness Constraint whose coverage is wider than Klein's original version.

\subsection{Klein (1992): P-Definiteness Constraint}

In order to solve the so-called present perfect puzzle, Klein introduces the $\mathrm{P}$ (osition)-Definiteness Constraint. Before entering into this constraint, we have to see the backgrounds necessary for the constraint. Let us first look at the definition of the notion of $p$-definite. Klein claims that "an expression whose lexical content explicitly specifies the position of a time span in relation to $\mathrm{TU}$ [i.e. the speech time] is 'pdefinite'” (p. 544). Hence, an expression accompanied by a DTP adverbial is p-definite: for example, She left Japan on March 29.

Let us then turn to a consideration of the peculiarity of the English present tense. Klein considers that the present tense is inherently pdefinite in that its reference time includes the speech time (S); since $\mathrm{S}$ is a prerequisite to any temporal relation, the position of $S$ has already been determined before an utterance. Hence, the peculiarity at issue is the inherent p-definiteness of the English present tense.

I will now proceed to the P-Definiteness Constraint: 
(20) P-DEFINITENESS CONSTRAINT: In an utterance, the expression of TT and the expression of TSit cannot both be independently p-definite. ${ }^{15}$

(Klein (1992: 546))

TT is short for the topic time and TSit for the time of situation. The former corresponds to the reference time and the latter to the event time. Notice that this constraint maximally allows only one p-definite expression in an utterance. Therefore the present perfect cannot go with a DTP adverbial without violating the constraint by virtue of the fact that the present perfect, a variant of the present tense, is inherently p-definite, as exemplified in (21):

(21) a. *Yoko has gone to Singapore on March 29.

b. *Mana has played the koto at four.

In Klein's view, each sentence has two p-definite expressions. In (21a) the TT (the reference time) is already p-definite in that it includes S, on the one hand, and the DTP adverbial on March 29 makes the TSit (the event time) p-definite, on the other. The same observation applies to (21b). Thus, they violate the P-Definiteness Constraint, and, accordingly, they are unacceptable. ${ }^{16}$

In contrast, the past tense is not inherently p-definite, since the topic time (i.e. the reference time) is not simultaneous with S. Thus, the preterite and the pluperfect, both of which are members of the past tense, can go with a DTP adverbial.

(22) a. Yoko went to Singapore on March 29.

b. Mana had played the koto at four.

There is only one p-definite expression in each sentence: on March 29 in (22a) and at four in (22b). Hence, they are both acceptable.

However, we can say that the following examples lower the value of

15 Klein (1992) defines the topic time as follows: "The topic time is the time span to which the claim made on a given occasion is constrained." (p. 535) The topic time is represented by the tense morpheme. As Klein (1992) himself suggests, we can regard the topic time as a kind of reference time.

16 An anonymous reviewer has questioned me as to the acceptability of a sentence like Now Yoko has gone to Singapore yesterday. This type of sentence is unacceptable in that it violates the P-Definiteness Constraint. In (3a), however, since the present perfect coocurs with now, the sentence apparently violates the constraint. Klein (1992: 549-550) regards time adverbials like now and today not as p-definite, but as "b(oundary)-definite", which means that the boundary (or interval) of a given expression is definite. This is supported by Comrie's (1985: 34) statement that the adverb now, together with the present perfect, is interpreted as 'up to now'. 
Klein's P-Definiteness Constraint: ${ }^{17}$

(23) a. At that time George had been to the dentist two hours earlier.

(Nakau (1994: 260))

b. When we arrived, our host had died a couple of hours earlier/before.

(Declerck (1991b: 364))

In (23a), for example, at that time specifies the reference time (our time of orientation) in the past and two hours earlier the event time; there are, thus, two p-definite expressions in (23a). Klein (1992: 545) argues that in a strict sense time adverbials like two hours earlier and five minutes ago do not make the event time p-definite, since such a time adverbial specifies a time interval before a certain time point; in (23a), for example, two hours earlier specifies an interval of two hours before the time point that at that time specifies. Under this view, it is certain that sentences like (23a) and (23b) are not counterexamples to the PDefiniteness Constraint.

If we proceed along these lines, however, we have to introduce one more constraint so as to explain why a time adverbial like five minutes ago cannot go with the present perfect: since, in Klein's view, such an adverbial is not p-definite, the unacceptability of a sentence like Yoko has eaten breakfast five minutes ago is not attributed to the violation of the P-Definiteness Constraint. One possible constraint is the so-called scope-contradiction constraint: the present tense, which refers to the present time, is contradictory to the adverbial five minutes ago, which refers to the past time by virtue of the idiosyncratic property of ago; so the present perfect cannot go with an adverbial like five minutes ago. In sum, under Klein's account, the unacceptability of a present perfect like Mana has played the koto at four and that of a present perfect like Yoko has eaten breakfast five minutes ago cannot be explained by a unified constraint.

17 Michaelis (1994) rejects the P-Definiteness Constraint, arguing that a sentence like the following impeaches its validity:

(i) It was 1972. Harry had joined the navy in 1960. (Michaelis (1994: 113)) She claims that although the reference time (i.e. Klein's topic time) is specified by 1972 and the event time by in 1960, it is not anomalous. However, Michaelis misunderstands Klein's P-Definiteness Constraint. 1972 specifies the R of the first sentence, not the $\mathrm{R}$ of the second sentence. The second sentence is not explicitly specified by two $\mathrm{p}$-definite time adverbs. The $\mathrm{p}$-definiteness of $\mathrm{R}$ of the second sentence is only implied by the $R$ of the first sentence. Discourse (i), thus, is not a counterargument to the P-Definiteness Constraint. 
If, however, we revise Klein's P-Definiteness Constraint on the basis of the dual structure of the perfect tense, then we can account, from a unified point of view, for both the grammaticality of sentences like those in (23) and the incompatibility of the present perfect with an adverbial like five minutes ago. In the next subsection, I will present a revised version of the P-Definiteness Constraint, and, then, examine its validity.

\subsection{Revised P-Definiteness Constraint}

This subsection deals with a revised version of the P-Definiteness Constraint. In section 3, I have shown that a finite perfect is composed of an absolute tense and the perfect tense (i.e. a relative tense), and that the situation with which the perfect tense is associated consists of two distinct sub-situations, i.e. E and E+. Given these, the revised P-Definiteness Constraint is defined as follows:

(24) Revised P-DEFINITENESS CONSTRAINT: In a clause, the absolute tense and the relative tense components cannot both be independently p-definite.

In what follows, I will examine the validity of the revised PDefiniteness Constraint. First of all, like Klein's original version, the revised version also sheds light on the incompatibility of the present perfect with a DTP adverbial. Recall that the present perfect is decomposed into the present tense (i.e. a member of absolute tenses) and the perfect tense (i.e. a member of relative tenses). The present tense is inherently p-definite because it entails the speech time within its temporal scope, i.e. within the time-sphere established by the present tense morpheme; ${ }^{18}$ thus, the absolute tense component of the present perfect, i.e. the present tense is always p-definite. Therefore the relative tense component, i.e. the perfect tense cannot be p-definite without violating the revised P-Definiteness Constraint; hence the unacceptability of (21a) and (21b).

It may be helpful to illustrate this in a diagram:

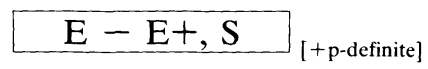

(Present Perfect)

18 A temporal scope is defined as a time-sphere that is established by a given tense. Thus, the temporal scope of the present tense and that of the past tense correspond to the present (or non-past) time-sphere and the past time-sphere, respectively. The length of a temporal scope is measured on the basis of our subjective judgment. 
The rectangle represents the temporal scope of an absolute tense (in this case the present tense). The schema in (25) shows that the perfect tense (symbolized by E-E+) is completely within the scope of the present tense. It is convincing to say that since the perfect tense is temporally subordinated to the present tense, the perfect tense is under the influence of the p-definiteness of the present tense. For this reason, we can claim that the perfect tense inherits p-definiteness from the present tense; thus, neither E nor E+ can be specified by a DTP adverbial like on March 29, since they are both the constituents of the perfect tense, i.e. the constituents of the relative tense component.

Secondly, the revised P-Definiteness Constraint can explain why the present perfect cannot go with an adverbial like five minutes ago: we need not regard, on an ad hoc basis, such an adverbial as an adverbial of time-interval specifying. We can construe it as a DTP adverbial, and, accordingly, regard it as being capable of making the relative tense component p-definite. In this view, a sentence in the present perfect like She has finished breakfast five minutes ago is ruled out because it has two p-definite expressions: the present tense and the DTP adverbial five minutes ago. We, thus, need not assume a constraint like the scope-contradiction constraint.

Now turn to the pluperfect. The absolute tense component of the pluperfect, i.e. the past tense is not inherently p-definite in that it does not include the speech time (S) within its temporal scope, i.e. within the time-sphere established by the past tense morpheme, as is clear from (26):

$$
E-E+, O-S \text { (Pluperfect) }
$$

The revised P-Definiteness Constraint, thus, allows the relative tense component, i.e. the perfect tense to be p-definite: either the $\mathrm{E}$ or the $\mathrm{E}+$ (or both) of the perfect tense can be specified by a DTP adverbial. In (23a) at that time specifies the $\mathrm{E}+$ and two hours earlier the $\mathrm{E}$, both of which are the constituents of the perfect tense; so only the relative tense component is p-definite. The same analysis goes for (23b). Hence, (23a) and (23b) do not violate the revised P-Definiteness Constraint, and so they are acceptable.

It should be noted here that a sentence like At seven, John had left at six is ungrammatical. The reason is ascribed to the violation of the revised P-Definiteness Constraint: at seven makes the absolute tense component p-definite, while at six makes the relative tense component 
p-definite. In this case both at seven and at six cannot be associated with the perfect tense (i.e. the relative tense component). This results from the semantic structure of the perfect tense. E and E+ constitute the whole situation that the perfect represents and are thus closely related to each other, whereas the time specified by at seven is separate from, and is not related to, the time specified by at six. Thus, at seven and at six cannot specify $\mathrm{E}+$ and $\mathrm{E}$ respectively.

This does not hold for (23a) and (23b). The fact that $E$ is connected to $\mathrm{E}+$ is compatible with the lexical property of earlier/before: the time specified by this type of adverbial (e.g. two hours earlier) presupposes the time to which it is related. From what we have seen so far, we can say that our revised P-Definiteness Constraint is more adequate than Klein's original one.

To sum up, the incompatibility of the English present perfect with a DTP adverbial is connected with the inherent p-definiteness of the English present tense. The perfect tense itself can go with DTP adverbials like at four and two hours earlier. Under this view, a pluperfect with a DTP adverbial like that in (2) is not an argument for the claim that the pluperfect can represent the pre-preterite tense.

\section{Consequences}

In this section, I will observe some empirical facts that are predicted and explained as consequences of my proposal.

\subsection{Indirect Speech}

The temporal schemata of the pre-perfect and the pre-preterite tenses can adequately explain the difference between the following sentences:

(27) a. One day, Naomi said to Oscar that she had seen him the day before.

b. One day, Naomi said to Oscar that she saw him the day before.

(Comrie (1986: 273))

Comrie (1986) notes that "the pluperfect will only be appropriate in cases where a reference point [our time of orientation] in the past can be contextually established." (p. 291) In both (27a) and (27b), however, the reference time in the past is contextually established by the time when Naomi talked to Oscar, more specifically, by the adverbial one day. It can thus be said that the temporal structure of 
the complement clause (CC) of (27a) is identical with that of the CC of (27b): in both cases, the event time is anterior to the reference time, which is, in turn, anterior to the speech time. Thus, within Reichenbach's system the CC in (27a) has the same temporal structure as that in (27b).

By contrast, our temporal system can explain the difference between (27a) and (27b). Within our system, the temporal structure of the preperfect tense is assigned to the CC of (27a) and that of the prepreterite tense to the $\mathrm{CC}$ of $(27 \mathrm{~b})$. The temporal schemata of both (27a) and (27b) are shown in (28):

(28) a. Temporal Structure for (27a)

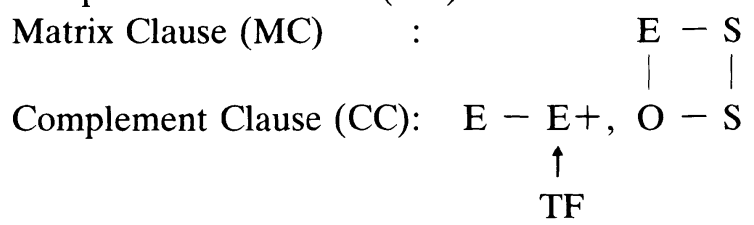

b. Temporal Structure for (27b)

\begin{tabular}{|c|c|}
\hline Matrix Clause (MC) & $E-S$ \\
\hline Complement Clause (CC): & $E-O-S$ \\
\hline
\end{tabular}

In both (27a) and (27b), the E of the MC (i.e. the time of Naomi's talking to Oscar) specifies the $\mathrm{O}$ of the CC. In (28b), what the temporal structure of the $\mathrm{CC}$ represents is that the situation of Naomi's seeing Oscar precedes the $\mathrm{O}$ in the past and the TF is fixed on the situation $\mathrm{E}$ itself. In (28a), on the other hand, the temporal structure of the CC entails not only the situation $\mathrm{E}$ but also the resultative state $\mathrm{E}+$ which obtains at the $\mathrm{O}$ in the past, and shows that the TF is fixed on the $\mathrm{E}+$; thus, there exists a link between the $\mathrm{E}$ of the $\mathrm{CC}$ and the $\mathrm{E}$ of the MC by virtue of the presence of the $\mathrm{E}+$.

Our analysis can be further supported by the following. Quirk et al. (1985: 1026-1027) state that "if the present deictic references in the direct speech became past deictic references in the indirect speech, there is a corresponding shift of verb forms into past, or if necessary into the past perfective." We can interpret this statement as follows: in the use of the indirect speech, we normally choose the preterite version; we choose the pluperfect version in cases where there is some information that the preterite cannot convey, i.e. the cases where the 
TF is situated on the resultative state $\mathrm{E}+$ which holds at the $\mathrm{O}$.

\subsection{After-Clauses}

As a second consequence of my proposal, the difference between the pluperfect and the preterite in after-clauses can be explained adequately. Let us begin by considering (29):

(29) a. After he had eaten his dinner, he smoked a cigar.

b. After he ate his dinner, he smoked a cigar.

(Salkie (1989: 2))

(29a) is said to be synonymous with (29b). It is certain that both (29a) and (29b) have the same temporal relation between the situation of the main clause (MC) and the situation of the subordinate clause (SC). However, it is not guaranteed that (29a) has the same temporal structure as $(29 \mathrm{~b})$.

Our system predicts and explains that they are different in the temporal structure of the SC, schematized as in (30); the pluperfect represents the pre-perfect tense and the preterite the pre-preterite tense:

$$
\begin{aligned}
& \text { a. Temporal Structure for (29a) } \\
& \text { Main Clause (MC) : } \quad \mathrm{E}-\mathrm{S} \\
& \text { Subordinate Clause (SC): } \quad \mathrm{E}-\underset{\uparrow}{\mathrm{E}+}, \mathrm{O}-\mathrm{S} \\
& \text { TF } \\
& \text { b. Temporal Structure for (29b) } \\
& \begin{array}{ll}
\text { Main Clause (MC) } & E-S \\
\text { Subordinate Clause (SC): } & \mathrm{E}-\mathrm{O}-\mathrm{S} \\
\uparrow & \mathrm{TF}
\end{array}
\end{aligned}
$$

As is self-evident from (30a), the pluperfect version shows that the $\mathrm{E}$ of the SC (i.e. his eating dinner) is relevant to the $\mathrm{E}$ of the $\mathrm{MC}$ (i.e. his smoking) by virtue of the presence of the $\mathrm{E}+$ of the SC. As is clear from (30b), by contrast, the preterite version only shows that the $\mathrm{E}$ of the SC precedes the E of the MC.

In this connection, Leech $(1987: 48)$ states that in the case of the pluperfect we measure the precedence of the situation of the SC from the time of the situation of the $\mathrm{MC}$; in the case of the preterite we measure the situation of the SC directly from the speech time (S). In 
our system, this contrast is explained in terms of the difference of the position of temporal focus (TF). In (29a) the TF is fixed on the resultative state $\mathrm{E}+$ of the $\mathrm{SC}$ (e.g. the state of feeling a full stomach), which coincides with the $\mathrm{E}$ of the $\mathrm{MC}$; the speaker can use the pluperfect to express a link between the $\mathrm{E}$ of the SC and the $\mathrm{E}$ of the $\mathrm{MC}$ by virtue of the presence of the $\mathrm{E}+$. In (29b), on the other hand, the TF is necessarily fixed on the $\mathrm{E}$ of the $\mathrm{SC}$ itself by virtue of the absence of the $\mathrm{E}+$; the speaker focuses, from $\mathrm{S}$, directly on the situation of his eating; hence no link of relevance between the $E$ of the $\mathrm{SC}$ and the $\mathrm{E}$ of the MC.

This line of reasoning is supported by the fact that we can replace (31a) with (31b), but not with (31c), without changing the temporal interpretation:

(31) a. John arrived after the bomb had exploded.

(Declerck (1991b: 108))

b. John arrived when the bomb had exploded.

(Declerck (1991b: 109))

c. John arrived when the bomb exploded.

Like (31a), (31b) is construed as follows: the MC time (i.e. the time of John's arrival) functions as the $\mathrm{O}$ of the $\mathrm{SC}$, which is simultaneous with the $\mathrm{E}+$ of the SC (i.e. the state of the place in question burned down), not with the $\mathrm{E}$ of the $\mathrm{SC}$ (i.e. the instant of the explosion). In the case of (31c), however, the MC time is connected with the E of the SC. If we draw on the position that when is supposed to express a relation of simultaneity, we can ascribe to the temporal structure of the pluperfect the reason why the $\mathrm{MC}$ is always related to the $\mathrm{E}+$ of the $\mathrm{SC}$ in a sentence like (31b). Since the pluperfect always requires the $\mathrm{TF}$ to be on the $\mathrm{E}+$, the speaker's attention is paid to the $\mathrm{E}+$; thus, the MC situation is always related to the $\mathrm{E}+$ of the $\mathrm{SC}$ via when. Taking into consideration the fact that both after-clauses and whenclauses are regarded as temporal clauses, we can say that the pluperfect in the former has the same structure as that in the latter. The reason why in after-clauses the preterite seems to express the same temporal relation as the pluperfect is due to the lexical property of after.

\subsection{Narrative Texts}

Finally, my proposal can account for the inconsistent use of the pluperfect in narrative texts. As is well known, the pluperfect is not always used to refer to a situation in the-past-in-the-past (Past 2) in a 
narrative. Consider:

(32) She left the bedroom to wash and dress in the bathroom down the hall. Michael, still naked, the morning sun refreshing his body, lit a cigarette and relaxed on the bed. This was the last morning they would spend in this house and the villa ....

The night before, Don Tommasino had sat with Michael in the garden after Apollonia had gone to bed. The Don had been worried and tired, and admitted that he was concerned about Michael's safety. "Your marriage brought you into sight," he told Michael ....

(M. Puzo, The Godfather, pp. 350-351, italics mine) The four italicized preterites in the first paragraph refer to the same time domain as the narrative-now, i.e. the present time in narrative texts. This time domain is labelled as Past 1 . The first two italicized pluperfects in the second paragraph refer to Past 2. What is crucial is that the preterites (i.e. admitted, was concerned, told) in the second paragraph also refer to Past 2, not to Past 1. As Fenn (1987: 220-221) points out, if the pluperfect were really the pre-preterite tense, it would logically be used throughout references to situations in Past 2; but this is not always the case. Moreover, it should also be noted that the pluperfect cannot be used to refer to Past 1. Given these facts, we can assume that the distribution of the verb forms in (32) implies that the preterite can function as the pre-preterite tense, whereas the pluperfect functions as the pre-perfect tense.

In order to verify this, let us begin with Inoue's (1979) statement that the present perfect conveys an explanatory sense. Inoue claims that a speaker chooses the present perfect "when the information he is giving or requesting appropriately exemplifies or explains the topic of discourse." (p. 585) The important point to note here is that the same discourse function applies to the pluperfect. Fenn (1987) states that "expository information in narrative texts is often conveyed in the past perfect" (p. 220). In (32), for instance, the first two pluperfects had sat and had gone describe preceding experiences (in Past 2) which convey some pieces of information relevant to the main events in the narrative-now (i.e. Past 1): the experiences in Past 2 (e.g. Don Tommasino's sitting with Michael warning him of the danger of his life) explain why Michael and Apollonia are forced to leave the place where they have been. This kind of parallel between the present perfect and 
the pluperfect supports my proposal.

Let us then turn to the question as to why and when the preterite, instead of the pluperfect, is used to refer to Past 2. The notion of temporal focus shifting (TFS) gives an answer to the question. According to Declerck (1991b), the TFS occurs when "there is a shift in what the speaker is concerned with." (p. 307) As Declerck mentions, it is generally admitted that in the use of the present perfect a speaker focuses on the fact that a given situation in the past (i.e. our E) is relevant to the structure of the world (within which our E+ is subsumed) at the speech time (S), whereas in the use of the simple past a speaker focuses on a situation in the past (i.e. our E) itself.

To capture this clearly, the temporal structures of both tenses are schematized as follows:

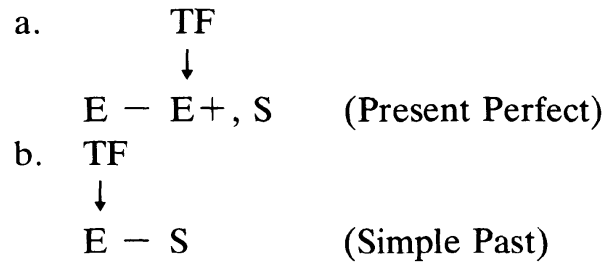

These temporal schemata can convincingly illustrate the distributional properties of the present perfect and the simple past in discourse. Observe:

(34) I have seen him already - he came to borrow a hammer. (Leech (1987: 40-41)) It is often pointed out that the present perfect functions as the first reference to some situation in discourse and the simple past describes the subsequent situations. Within our system, it can be predicted that this phenomenon results from the difference between the temporal structures of the present perfect and the simple past. In the case of the present perfect the TF is fixed on the $\mathrm{E}+$ which obtains at $\mathrm{S}$. Since $S$ is the only time that both a speaker and a hearer can always share without a special effort, discourse starts with the present perfect which requires the TF to be on the situation (i.e. E+) that obtains at $\mathrm{S}^{19}$ Once both a speaker and a hearer share knowledge of the

19 Discourse often starts with the simple past like the following:

(i) A: Did you read the book?

B: Yes, it was interesting.

In this case speaker $\mathrm{A}$ and speaker $\mathrm{B}$ share the same knowledge about the topic. 
situation in question (i.e. the situation in the past), they can easily identify and thus focus on that situation. The TF, thus, shifts from the $\mathrm{E}+$ in the present time to the $\mathrm{E}$ in the past. As a consequence, we choose the simple past.

I am now in a position to consider the shift from the pluperfect to the preterite. Before going further, it may be helpful to repeat the temporal schemata of the pre-perfect and the pre-preterite tenses, here as (35):

(35)

$$
\text { a. } \begin{gathered}
\mathrm{TF} \\
\\
\mathrm{E}-\mathrm{E}+, \mathrm{O}-\mathrm{S}
\end{gathered}
$$

(Meaning: Pre-perfect; Form: Pluperfect)

b. TF

$$
\downarrow
$$

Let us now look at the excerpt in (32) again. To see it clearly, I represent the temporal relation of verbs in (32) diagrammatically as follows:

\begin{tabular}{|c||l|}
\hline $\begin{array}{c}\text { Past } 1 \text { (Narrative-Now: The } \\
\text { Morning) }\end{array}$ & left, lit, relaxed, was \\
\hline Past 2 (The Night Before) & $\begin{array}{l}\text { had sat, had gone, admit- } \\
\text { ted, was concerned, told }\end{array}$ \\
\hline
\end{tabular}

In the first two pluperfects (i.e. had sat and had gone) the TF is situated on the state $\mathrm{E}+$ at the narrative-now, i.e. Past 1 . The reason why the second paragraph starts with the pluperfect is that in narrative texts the narrative-now is the time domain that the narrator and the reader(s) can always share without a special effort (see (35a)). The narrator shifts the TF from the E+ in Past 1 to the E in Past 2 after his concern has switched to the $\mathrm{E}$ in Past 2. Thus, the preterites (i.e. admitted, was concerned and told) are used which require the TF to be on a given situation $\mathrm{E}$ itself. This is similar to the pattern of the TFS from the present to Past 1 . We can therefore conclude that the TFS motivates the shift of verb form from the pluperfect to the preterite.

They both know what book is at issue. Therefore speaker A can begin with the preterite which requires the TF to be fixed on the situation $E$ in the past. 


\section{Conclusion}

This paper has shown that the English pluperfect does not represent the pre-preterite tense, but represents only the pre-perfect tense.

We have pursued the following steps. First, I have offered two phenomena that count as arguments against the pre-preterite interpretation of the pluperfect. Secondly, taking the position that a finite perfect is factored into an absolute tense and the perfect tense (i.e. a relative tense), I have claimed that a nonfinite perfect represents the intrinsic meaning of the perfect tense. Thirdly, I have argued that the perfect tense is associated with two sub-situations, i.e. a given situation and a corresponding resultative state; and, following Declerck (1991a, b), I have divided the reference time into the time of orientation and the temporal focus. Taking all these things into consideration, I have formulated the temporal schemata of the pre-perfect and the pre-preterite tenses. Fourthly, I have shown, by revising Klein's PDefiniteness Constraint, that the incompatibility of the present perfect with a DTP adverbial is due to the inherent p-definiteness of the English present tense. Finally, I have demonstrated that our temporal system accounts appropriately for the distributional differences between pluperfect and preterite in indirect speech clauses, after-clauses, and narrative texts.

\section{REFERENCES}

Ando, Sadao (1983) Eigokyoshi no Bunpo Kenkyu, Taishukan, Tokyo.

Binnick, Robert I. (1991) Time and the Verb, Oxford University Press, Oxford. Comrie, Bernard (1985) Tense, Cambridge University Press, Cambridge.

Comrie, Bernard (1986) "Tense in Indirect Speech," Folia Linguistica 20, 265-296.

Declerck, Renaat (1991a) A Comprehensive Descriptive Grammar of English, Kaitakusha, Tokyo.

Declerck, Renaat (1991b) Tense in English: Its Structure and Use in Discourse, Routledge, London.

Fenn, Peter (1987) A Semantic and Pragmatic Examination of the English Perfect, Narr, Tübingen.

Frawley, William (1992) Linguistic Semantics, Lawrence Erlbaum Associates, New Jersey.

Grice, H. Paul (1975) "Logic and Conversation," Syntax and Semantics 3: 
Speech Acts, ed. by Peter Cole and Jerry L. Morgan, 41-58, Academic Press, New York.

Hornstein, Norbert (1990) As Time Goes By: Tense and Universal Grammar, MIT Press, Cambridge, MA.

Huddleston, Rodney (1984) Introduction to the Grammar of English, Cambridge University Press, Cambridge.

Inoue, Kyoko (1979) “An Analysis of the English Present Perfect," Linguistics 17, 561-589.

Jespersen, Otto (1931) A Modern English Grammar on Historical Principles IV, George Allen and Unwin, London.

Klein, Wolfgang (1992) "The Present Perfect Puzzle," Language 68, 525-552.

Klein, Wolfgang (1994) Time in Language, Routledge, London.

Lascarides, Alex and Nicholas Asher (1993) "Temporal Interpretation, Discourse Relations and Commonsense Entailment," Linguistics and Philosophy 16, 437-493.

Leech, Geoffrey N. (1987) Meaning and the English Verb, 2nd ed., Longman, London.

McCawley, James D. (1971) "Tense and Time Reference in English," Studies in Linguistic Semantics, ed. by Charles J. Fillmore and D. Terence Langendoen, 97-113, Holt Rinehart and Winston, New York.

Michaelis, Laura A. (1994) "The Ambiguity of the English Present Perfect," Journal of Linguistics 30, 111-157.

Nakau, Minoru (1985) "Imiron no Genri 19: Raihenbahha Jiseiron Hihan (Principles of Semantics 19: Critique of Reichenbach's Tense System)," Eigo Seinen 131.7, 24-26.

Nakau, Minoru (1994) Ninchi Imiron no Genri (Principles of Cognitive Semantics), Taishukan, Tokyo.

Parsons, Terence (1990) Events in the Semantics of English: A Study in Subatomic Semantics, MIT Press, Cambridge, MA.

Quirk, Randolph, Sidney Greenbaum, Geoffrey Leech and Jan Svartvik (1985) A Comprehensive Grammar of the English Language, Longman, London.

Reichenbach, Hans (1947) Elements of Symbolic Logic, Free Press, New York.

Salkie, Raphael (1989) "Perfect and Pluperfect: What Is the Relationship?" Journal of Linguistics 25, 1-34.

Kasumi-Haitu C 211

3-2-1 Amakubo

Tsukuba-shi

Ibaraki 305 